\title{
A DOCÊNCIA NA LICENCIATURA INTERCULTURAL INDÍGENA: SABERES DA LITERATURA DE TRADIÇÃO ORAL
}

\author{
THE TEACHING IN INDIGENOUS INTERCULTURAL LICENCIATURE: \\ KNOWLEDGE OF ORAL TRADITION LITERATURE
}

\section{LA DOCENCIA EN LA LICENCIATURA INTERCULTURAL INDÍGENA: SABERES DE LA LITERATURA DE TRADICIÓN ORAL}

\author{
Márcia de Souza ${ }^{1}$, Cíntia Márcia da Silva Guisso², Felipe Flores Kupske ${ }^{3}$
}

\begin{abstract}
RESUMO
Este trabalho apresenta situações de aprendizagem da prática de estágio de Língua Portuguesa, Língua Kaingang e Literaturas, do Curso de Licenciatura Intercultural Indígena em Línguas, Artes e Literaturas, da Unochapecó. As atividades foram realizadas com o ensino fundamental e médio, na Escola Cacique Vanhkre, em Ipuaçu, Santa Catarina. Optamos pelo trabalho com as histórias da tradição oral, por entendermos que elas transmitem ensinamentos, sugerem percepções distintas dos modos de viver dos povos e das culturas em diferentes épocas históricas. Nelas encontramos referências culturais dos antepassados e da sua organização comunitária. Entendemos como prioridade, nas comunidades indígenas, instigar as crianças e adolescentes a valorizar as experiências dos mais velhos e a reconhecer a força que essas histórias têm para a revitalização da cultura do Povo Kaingang. As histórias, os causos, as lendas que os velhos kaingang contam, trazem referências do imaginário e dos valores desse povo. Os velhos devem ser observados como legítimos acervos, bibliotecas ativas e os professores precisam descobrir e fazer uso desses bens culturais para que os conhecimentos sejam transmitidos às gerações. A experiência do estágio significou uma possibilidade para incentivar as crianças e os adolescentes a ler, escrever e conhecer aspectos da cultura indígena. Trabalhamos com as lendas do acervo memorialista da indígena Dona Pureza da Conceição Oliveira. As narrativas foram coletadas por familiares e socializadas com os estudantes. Por meio da linguagem poética da tradição popular, foi possível perceber situações que envolvem os modos de conviver e de compreender o presente, com uma visão crítica. Realizamos um trabalho prazeroso, sem com isto se afastar da Lei de Diretrizes e Bases da Educação Nacional, a qual enfatiza a diferenciação da escola indígena das demais escolas do sistema educacional.
\end{abstract}

PALAVRAS-CHAVE: Literatura. Cultura. Educação Indígena. Interculturalidade.

\section{ABSTRACT}

This work presents learning situations of the Portuguese Language, Kaingang Language and Literatures internship practice of the Indigenous Intercultural Licentiate Course in Languages, Arts and Literatures, of Unochapecó. The activities were accomplished with elementary and high school, at Cacique Vanhkre School, in Ipuaçu, Santa Catarina. We have chosen to work with the oral tradition stories, because we understand that they convey teachings, suggest different perceptions about ways of peoples living and cultures in different historical

\footnotetext{
${ }^{1}$ Doutora e Mestre em Literatura pela Universidade Federal de Santa Catarina UFSC. Professora Titular do Curso de Letras e do Curso de Licenciatura Intercultural Indígena em Línguas, Artes e Literaturas da Universidade Comunitária da Região de Chapecó (Unochapecó). E-mail: marcias @unochapeco.edu.br

${ }^{2}$ Mestre em Educação e graduada em Licenciatura Intercultural Indígena em Línguas, Artes e Literaturas, pela Universidade Comunitária da Região de Chapecó (Unochapecó). Professora na EIEB Cacique Vanhkre. E-mail: cintiamarcia@unochapeco.edu.br

${ }^{3}$ Doutor em Linguística Aplicada pela Universiade Federal do Rio Grande do Sul (UFRGS) e Mestre em Letras pela Universidade Federal de Santa Maria (UFSM). Professor titular da Universidade Federal da Bahia (UFBA). E-mail:kupske@gmail.com
}

\begin{tabular}{c|c|c|c}
\hline Rev. Ciências Humanas & Frederico Westphalen, RS & Pg. 05-18 & Maio/Agosto 2019 \\
\hline \multicolumn{2}{c}{ Recebido em: $12 / 06 / 2019$} & Aceito em: $15 / 08 / 2019$ \\
\hline
\end{tabular}




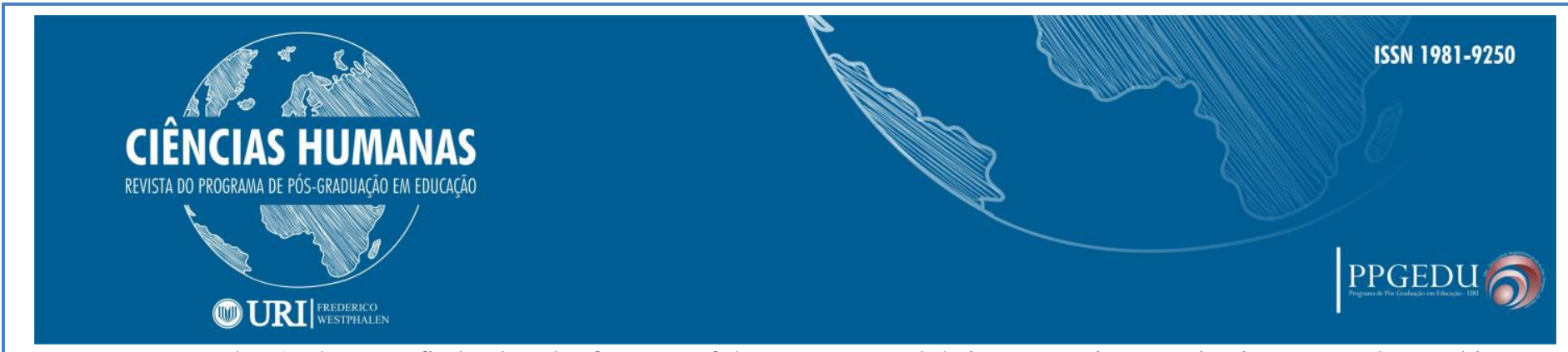

epochs. At them we find cultural references of the ancestors and their community organization. We understand it is a priority, at indigenous communities, to encourage children and teenagers to value elders experiences and to recognize the strength that these histories have for the Kaingang People culture revitalization. The stories, the tales, the legends that the old Kaingang people tell, bring references from the imaginary and the values of this people. Old people must be observed as legitimate collections, active libraries and teachers must discover and make use of these cultural assets, so knowledge can be transmitted to the generations. The internship experience meant a possibility to encourage children and teenagers to read, write and learn about indigenous culture aspects. We worked with legends from memorialist collection of the indigenous Ms. Pureza da Conceição Oliveira. The narratives were collected by relatives and socialized with the students. Through the poetic language of popular tradition, it was possible to realize situations that involve the living together ways and understand the present, with a critical view. We did a pleasant job, without departing from the Law of Guidelines and Bases of National Education, which emphasizes the differentiation of the indigenous school from other schools in the educational system.

Keywords: Literature; Culture; Indigenous Education; Interculturality.

\section{RESUMEN}

Este artículo presenta situaciones de aprendizaje de la etapa portuguesa de la práctica, kaingang Lengua y Literatura, Indígena Intercultural Licenciatura en Lenguas, Artes y Literatura, el Unochapecó. Las actividades se realizaron con la enseñanza fundamental y media, en la Escuela Indígena Cacique Vanhkre, en Ipuaçu, Santa Catarina. Optamos por el trabajo con las historias de la tradición oral, por entender que ellas transmiten enseñanzas, sugieren percepciones distintas de los modos de vivir de los pueblos y de las culturas en diferentes épocas históricas. En ellas encontramos referencias culturales de los antepasados y de su organización comunitaria. Entendemos como prioridad, en las comunidades indígenas, instigar a los niños y adolescentes a valorar las experiencias de los más viejos ya reconocer la fuerza que esas historias tienen para la revitalización de la cultura del Pueblo Kaingang. Las historias, los causos, las leyendas que los viejos kaingang cuentan, traen referencias del imaginario y de los valores de ese pueblo. Los viejos deben ser observados como legítimos acervos, bibliotecas activas y los profesores necesitan descubrir y hacer uso de esos bienes culturales para que los conocimientos sean transmitidos a las generaciones. La experiencia de la etapa significó una posibilidad para animar a los niños y adolescentes a leer, escribir y conocer aspectos de la cultura indígena. Trabajamos con las leyendas del acervo memorialista de la indígena Doña Pureza de la Conceição Oliveira. Las narrativas fueron recogidas por familiares y socializadas con los estudiantes. Por medio del lenguaje poético de la tradición popular, fue posible percibir situaciones que involucran los modos de convivir y de comprender el presente, con una visión crítica.

PALABRAS CLAVE: Literatura. Cultura. Educación Indígena. Interculturalidad.

\section{INTRODUÇÃO}

De acordo com as diretrizes previstas nos Parâmetros Curriculares Nacionais - PCNs (BRASIL, 1998) para a organização dos currículos do Ensino Fundamental e Médio, os Referencias para Formação de Professores Indígenas (BRASIL, 2002), bem como as referências nacionais para as escolas indígenas, as atividades que envolvem o estudo da língua portuguesa e literatura devem considerar a dimensão social que os processos de aprendizagem apresentam na trajetória da construção da cidadania, abrangendo conteúdos que tenham relevância social e sejam potenciais significativos para o desenvolvimento das habilidades de ler, escrever, falar e ouvir nas línguas Kaingang ou Guarani e Portuguesa. Mesmo as comunidades monolíngues em português mantem o traço identitário com o uso da língua dos

\begin{tabular}{c|c|c|c}
\hline Rev. Ciências Humanas & Frederico Westphalen, RS & Pg. 05-18 & Maio/Agosto 2019 \\
\hline Recebido em: $12 / 06 / 2019$ & Aceito em: 15/08/2019 \\
\hline
\end{tabular}




\section{CIÊNCIAS HUMANAS}

REVISTA DO PROGRAMA DE PÓS-GRADUAĞ̈O EM EDUCAĞ̄o

\section{(10)URI| |Rrbirke}

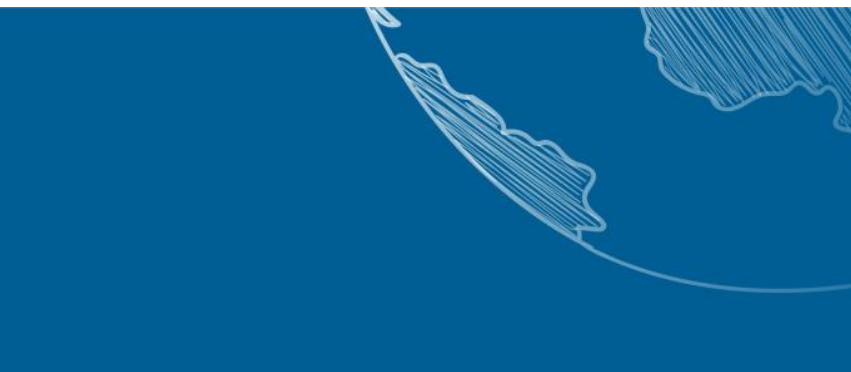

ancestrais e assim constituem o aspecto do bilinguismo.

As populações e as escolas indígenas convivem com várias situações diferentes de multilingüismo.[...] Não é raro encontrar, numa mesma aldeia, indivíduos monolingues em língua indígena, monolingues em língua portuguesa, bilíngües/multilíngües ativos (a pessoa entende e fala duas ou mais línguas) e bilíngües/multilíngües receptivos (a pessoa entende duas ou mais línguas, mas não fala todas elas). (BRASIL, 1998, p.116).

Dada essa realidade, os estudos que envolveram a elaboração das atividades do estágio curricular, na Licenciatura Intercultural Indígena em Línguas, Artes e Literaturas, foram orientados com base nos seguintes documentos: a) Referenciais para a Formação de Professores Indígenas (BRASIL, 2002). b) Referencial Curricular Nacional para as Escolas Indígenas - RCNEI (BRASIL, 1998) A leitura, análise e compreensão desses documentos foram essenciais para o planejamento das aulas, uma vez que eles apontam os objetivos e diretrizes para a educação indígena e não indígena, devendo prioritariamente ser de conhecimento de todos os envolvidos em processos de aprendizagem.

A Lei de Diretrizes e Bases da Educação Nacional (BRASIL, 1996) enfatiza a diferenciação da escola indígena das demais escolas do sistema educacional. Isto se dá pelo respeito à diversidade cultural, à língua materna e interculturalidade. Deste modo, o estudo dos Referenciais para a Formação de Professores Indígenas (BRASIL, 2002) e do Referencial Curricular de Educação Fundamental objetivou subsidiar o trabalho educativo na comunidade indígena e as ações previstas para o estágio curricular.

A compreensão desses documentos é relevante, pois assinalam conteúdos e discussões pedagógicas resultantes da participação de educadores indígenas e não indígenas, indicando questões comuns a todos os professores e instituições educacionais. São ferramentas que tornam compreensíveis e também incentivam a pluralidade e a diversidade nas ações curriculares, contribuindo para o fortalecimento das discussões pedagógicas em âmbito escolar e para a elaboração dos projetos educativos, decorrentes do diagnóstico, considerando a qualificação e as especificidades da educação escolar indígena.

Desse modo, as estratégias adotadas e que na sequência serão relatadas pela acadêmica Cíntia Márcia da Silva Guisso, levaram em conta a necessidade de construir com o estudante as condições necessárias para ampliar o domínio das línguas e da literatura, por se tratar de aprendizagem fundamental para o exercício da cidadania. Dessa estratégia resultou a

\begin{tabular}{l|c|c|c}
\hline Rev. Ciências Humanas & Frederico Westphalen, RS & Pg. 05-18 & Maio/Agosto 2019
\end{tabular}




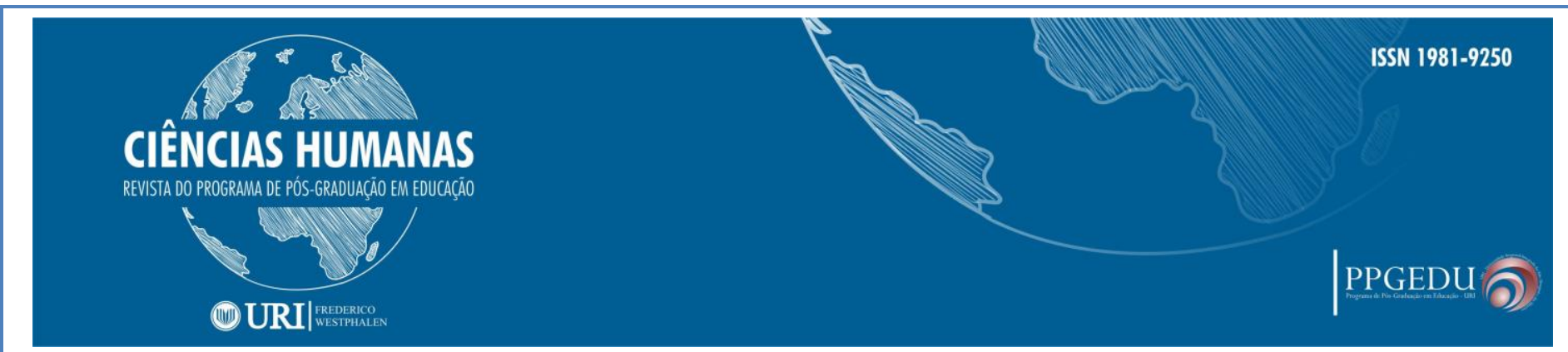

necessidade de os conteúdos do estágio em Línguas, Artes e Literaturas serem desenvolvidos de modo interdisciplinar.

Os planejamentos elaborados coletivamente propuseram o processo de aprendizagem de modo que os estudantes fossem capazes de desenvolver seus conhecimentos discursivos e linguísticos, aperfeiçoando os modos de ler e escrever conforme seus propósitos e demandas sociais; expressar-se apropriadamente em situações de interação oral considerando para isto aspectos diferentes daqueles do seu cotidiano; refletir sobre os fenômenos da linguagem, sobre a questão da variedade linguística, colocando-se teórica e criticamente diante das marcas estigmatizadas, da discriminação e dos preconceitos relativos ao uso da língua.

O sujeito expande sua capacidade de uso da linguagem e de reflexão sobre ela em situações significativas de interlocução. As propostas metodológicas de ensino de línguas foram organizadas de modo a considerar o texto (oral ou escrito) como unidade fundamental de trabalho, tendo em vista a diversidade de textos que circulam socialmente e a necessidade de identificá-los.

As atividades foram organizadas de maneira a tornar possível a análise crítica dos discursos, para que o estudante pudesse identificar pontos de vista, valores e possíveis preconceitos neles veiculados. O ensino de Línguas assim organizado se constituiu em fonte efetiva de autonomia para os sujeitos, condição para a participação social responsável e consequente produção de conhecimento.

\section{PRÁTICAS DE ESTÁGIO: EXPERIÊNCIAS DO PROFESSOR INDÍGENA COM O ENSINO DE LITERATURA}

Os nossos conhecimentos ancestrais ${ }^{4}$, vêm sendo pesquisados com pessoas mais velhas da comunidade. A nossa biblioteca são os velhos da aldeia. Eles não têm o conhecimento universal científico, mas mantêm o conhecimento ancestral. Tenho muito orgulho em morar na aldeia, é um privilégio poder ouvir as histórias que são contadas pelos nossos velhos. Sempre falamos que em nossa família temos um tesouro, e com a caminhada no tempo continua proporcionando parte de sua herança que é contar histórias. Para D’Angelis,

\footnotetext{
${ }^{4}$ Relato da acadêmica Cíntia Márcia da Silva Guisso.

\begin{tabular}{l|c|c|c}
\hline Rev. Ciências Humanas & Frederico Westphalen, RS & Pg. 05-18 & Maio/Agosto 2019 \\
\hline
\end{tabular}

\begin{tabular}{l|l} 
Recebido em: 12/06/2019 & Aceito em: 15/08/2019
\end{tabular}
}




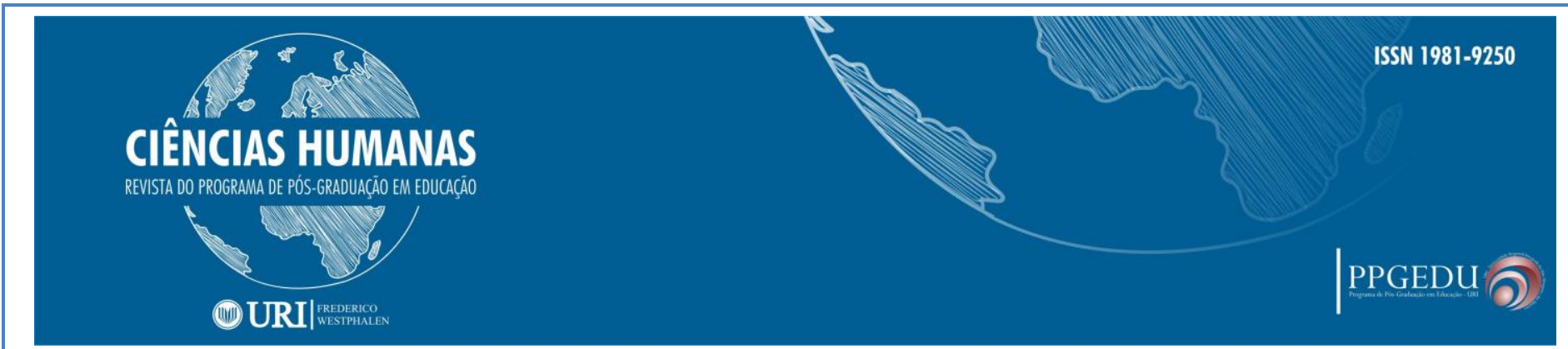

E também é parte da identidade de cada povo a sua própria história: lembrar dos seus antepassados, dos que criaram as coisas que são importantes para ele, e até considerar os seus antepassados como as pessoas mais importantes da história do mundo. Tudo isso é parte da identidade, isto é, da maneira como um povo - uma etnia - vê e valoriza a si mesmo. É só em situações de muito sofrimento e perseguição que as pessoas começam a querer trocar a sua identidade, e às vezes, chegam a ter vergonha da sua história, da sua gente, das formas próprias de vida criadas por seus antepassados. (D’ANGELIS, 2002, p.110).

Eu cresci ouvindo histórias contadas pela minha avó, fosse na sombra de uma árvore ou ao redor de um foguinho no chão. São riquezas conquistadas no dia a dia, não se trata de riquezas materiais, mas das riquezas culturais como o conhecimento das lendas. Nas diferentes sociedades indígenas "existem pessoas que desenvolvem conhecimentos específicos a respeito de certas categorias ou modalidades artísticas. Há sempre alguém [...] que sabe contar histórias com mais riqueza de detalhes e domina o estilo de narração. (RCNEI, 1998, p. 289).

Jyjy: kãtó (bengala), da etnia Kaingang, minha avó, Pureza da Conceição Oliveira, natural de Mangueirinha, no estado do Paraná, nasceu em 30 de junho de 1907. Foi com ela que aprendi a importância da tradição oral para a nossa cultura. Na sala de aula, sempre procurei fazer a ligação entre a literatura brasileira e literatura indígena, com algumas lendas contadas pela por ela. E aproveitei dessas experiências para organizar as minhas aulas no estágio obrigatório do ensino fundamental, do curso de Licenciatura Intercultural Indígena em Línguas, Artes e Literaturas.

A abordagem desse tema que envolve o reconhecimento da nossa cultura de tradição oral, deu-se pela necessidade de resgatar os valores culturais, além de despertar nos alunos o interesse pela leitura e escrita. As lendas são uma forma de expressão espontânea da nossa cultura kaingang, é uma herança deixada pelos nossos antepassados e pode ser transmitida aos alunos por meio de brincadeiras, adivinhas, danças, músicas, comidas típicas, crenças, narrativas, ou seja, em diferentes momentos do dia a dia.

Para colocar uma problematização ao tema, comecei a aula com as seguintes perguntas: o que é lenda? Por que as lendas kaingang são importantes para nosso povo? Quais são as lendas kaingang mais conhecidas? A partir do levantamento dessas questões, os alunos anotavam no caderno os saberes prévios, o que entendiam por lenda. Coletivamente, fomos elaborando e dispondo no quadro um conceito de lenda, como demostra a imagem, 


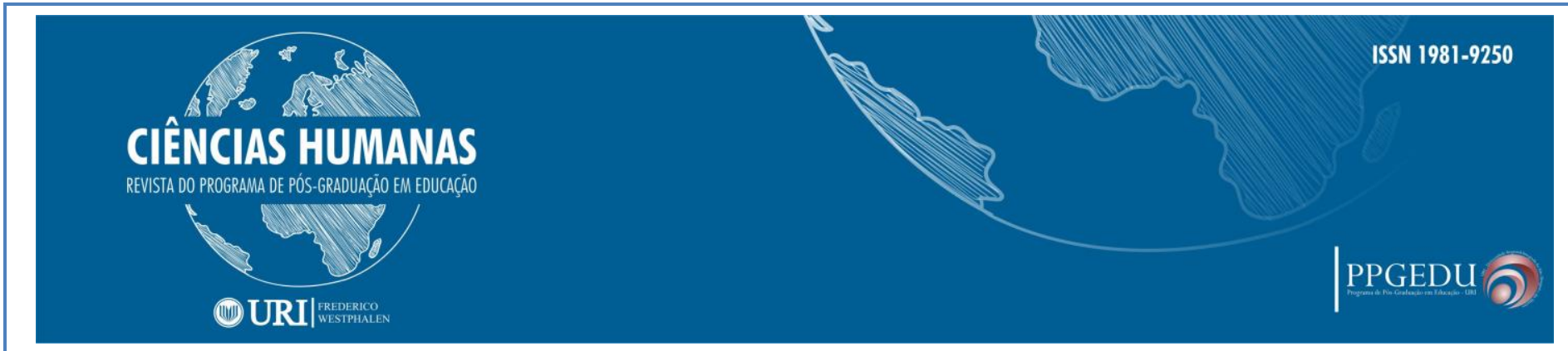

organizamos palavra por palavra que se encontravam recortadas em um balaio. Cada aluno pegava um pedaçinho de papel, para montarmos o conceito de lenda e, em seguida, verificarmos se ele coincidia com a resposta que os alunos tinham construido em seus cadernos.

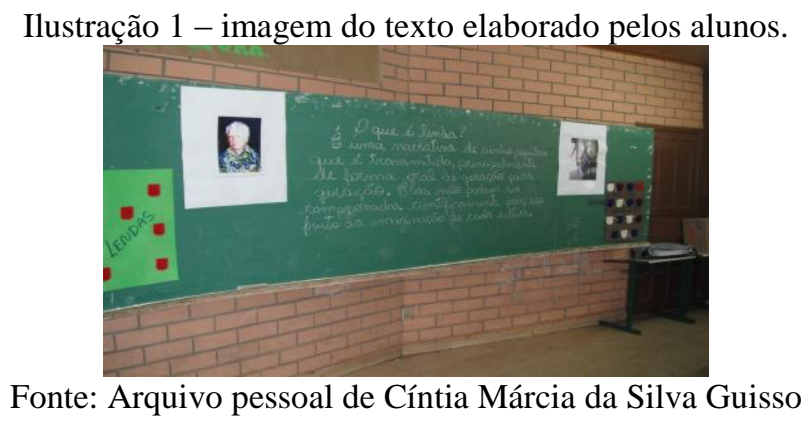

O Aluno que se sentia à vontade, dirigia-se à frente para falar um pouco sobre lenda e folclore. E claro, eu também contribuia para deixá-los mais à vontade. Os registros mostram o que fomos desenvolvendo com as lendas. Mas sempre fazendo uma relação com as lendas de autores que tínhamos lido, a exemplo de Jean de La Fontaine e Charles Perrault, escritores do século XVII, Irmãos Grimm e Hans Christian Andersen, ambos do século XIX e o brasileiro Monteiro Lobato, escritor do século XX. Muitas dessas histórias trazem referências que podem ser pensadas à luz de fOtos do cotidiano das crianças e jovens indígenas.

Ilustração 2 - Livro-objeto

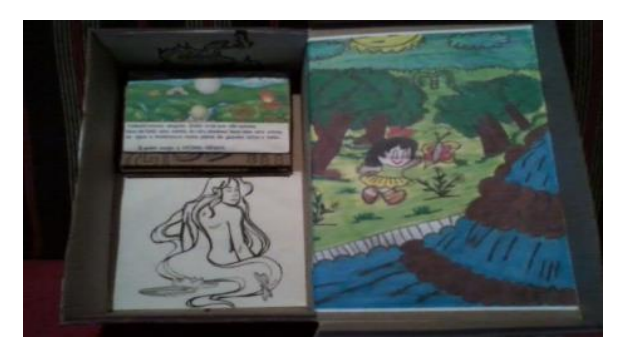

Fonte: Arquivo pessoal de Cíntia Márcia da Silva Guisso

Tendo como base a lenda Mãe d'água, muito difundida entre o povo kaingang, a qual também é conhecida no folcolore brasileiro como Iara, os alunos tiveram que construir um livro-objeto elaborado com imagens desenhadas pelos alunos e textos por eles produzidos. Assim fizemos a combinação da literatura com imagens. Aos poucos, através do modo que os desenhos foram organizandos, a história era contada. Essa atividade teve a intenção de 


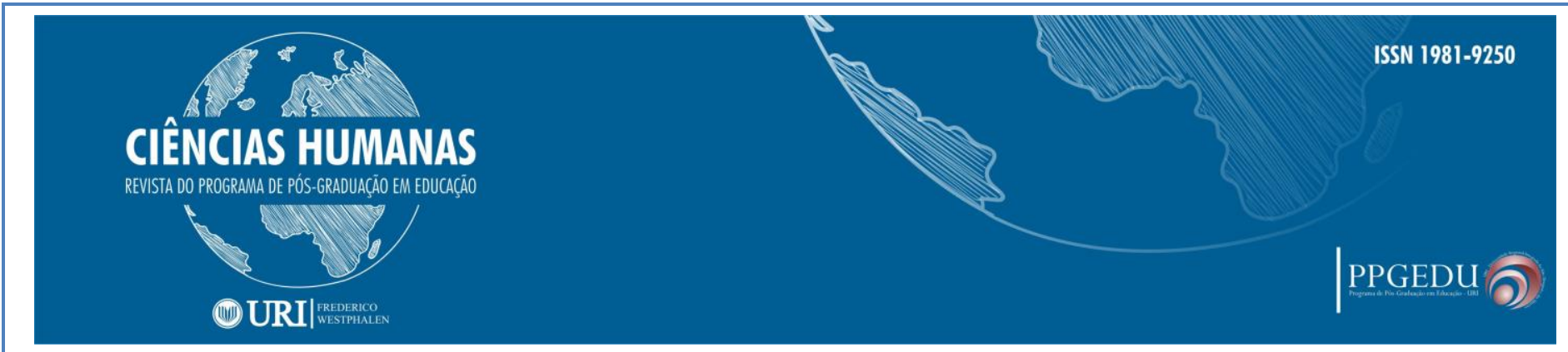

mostrar aos alunos que eles também são capazes de elaborar e reelaborar histórias. A confecção do livro-objeto também queria romper com a noção tradicional de livro, buscando uma identificação com os alunos, já que a compreensão da história depende da interpretação pessoal das imagens, ou seja, da interação humana.

O trabalho com uma lenda da tradição cultural brasileira, serviu de introdução para a elaboração de atividades com outros textos da tradição cultural kaingang, a exemplo da lenda do Sikré e da História do Sapo, as quais apresentarei a seguir, do modo como são contadas e se propagam entre nós.

\section{a) Lenda do Sikré}

Como a velha indígena Pureza da Conceição Oliveira contava, Sikré é um passarinho que vive nas margens dos rios. Gosta de voar e sentar em pedras, ficando sempre próximo ao rio. Toma banho todos os dias. É mais pequeno que um beija-flor. Quando pessoas se aproximam, voa sobre o rio corrente, não voa em outras direções. Havia um homem que era o dono do fogo, que na língua kaingang é pi tãn. Ele não dava fogo para ninguém. O pi tãn tinha uma filha que sempre ia buscar água no rio para tomar.

Um dia sikré pensou e disse:

- Como é que vou fazer para pegar um pi tãn? A! Já sei o que vou fazer amanhã! Quando a filha do pi tãn vier buscar, vou cair na água, vou fingir que estou quase morrendo e vou ver o que ela vai fazer. Eu sei que ela vai me lavar e vai me por perto do fogo para me enxugar, quando eu estiver enxuto! Eu roubo um pedaço de pau de lenha que tiver acesso e vou colocando fogo nos capinzais para que todos tenham fogo.

E foi exatamente o que fez. Assim que acabou de se enxugar, pegou um pedacinho de tição de fogo e mais que depressa voou pelo capinzal, ateando fogo. Então sikré gritou:

- Olhem fogo! Fogo, fogo. Foi assim que todos conheceram o fogo.

\section{b) História do Sapo}

Segundo Dona Pureza da Conceição Oliveira, antigamente o sapo era um animal muito bonito e comprido. Um dia, houve uma festa no céu, mas os sapos não foram convidados. Os gaviões ficaram felizes, pois tinham muita inveja dos sapos, por eles serem bonitos, mas como os sapos são espertos encontraram um jeitinho de ir à festa escondidos na viola dos gaviões mais novos, assim eles não notariam que estavam tão pesados. Quando 


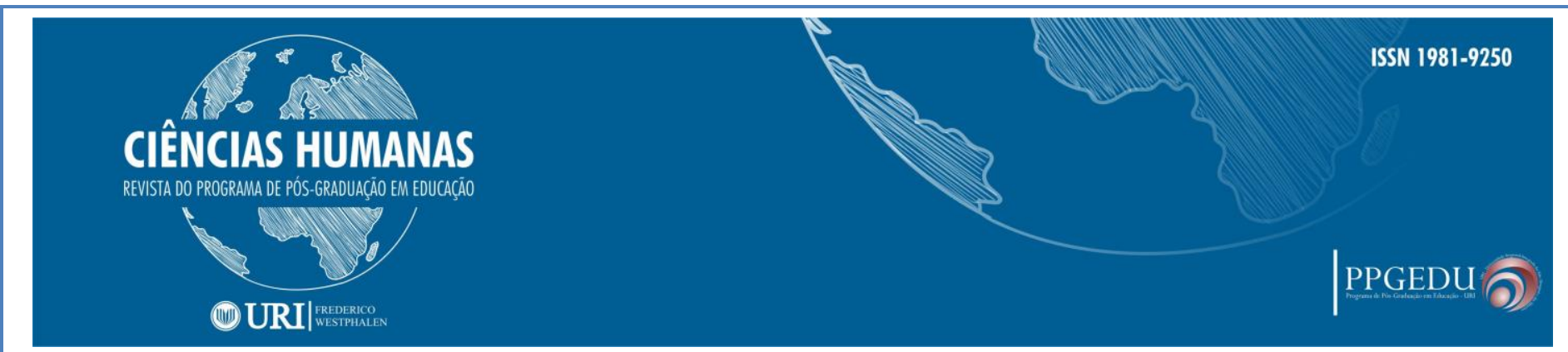

chegaram na festa, os gaviões deixaram a viola encostada perto do ninho dos gaviões pequenos, então os sapos foram saindo de fininho sem que ninguém os notasse. Mas lá pelas tantas, os gaviões guardiões avistaram os sapinhos e foi aquela briga.Os sapos começaram a lutar contra os gaviões. Os gaviões jogaram os sapinhos lá de cima e os coitadinhos caíram em cima das pedras. A pancada nas pedras foi tão forte que os sapos ficaram todos achatados. E assim não conseguiram mais voltar ao normal. O castigo foi ficar para sempre achatados, por provocarem brigas nas festas em que participavam.

\title{
A LITERATURA DE TRADIÇÃO ORAL NA SALA DE AULA: AS LENDAS INDÍGENAS
}

$\mathrm{Na}$ prática de estágio, no ensino fundamental e médio, o trabalho com as lendas auxiliou na construção de conhecimentos e na discussão de fatos que nem sempre o livro didático consegue explicar, como ocorre no reconhecimento dos processos interculturais da literatura de tradição oral. Em trabalho de pesquisa realizado em $1954^{5}$ e que fora reorganizado em nova edição em 2017, Silvio Romero afirma,

\begin{abstract}
As lendas de origem indígena e africana têm aqui e ali os seus congêneres. [...] Dos encontros e paralelismos que então descobrimos, damos apenas aqui um caso. $\mathrm{O}$ mito cósmico dos nossos índios, com que explicam a separação do dia e da noite, tem bastante analogia com a lenda da Nova Zelândia, que dá conta da separação do céu e da terra. (ROMERO, Sílvio, 2017, p.16).
\end{abstract}

É preciso reconhecer que as lendas trazem elementos fundacionais da cultura de um povo, ignorá-las no processo de aprendizagem escolar é negar o imaginário popular, repleto de sabedoria. Na prática do estágio, pudemos discutir com os estudantes, questões como, que valores e compreensões de mundo ou de um modo de viver essas narrativas apresentam? Como será possível manter viva a tradição cultural indígena de narrar histórias? Por meio de perguntas mobilizamos a aprendizagem e também buscamos despertar nos alunos o hábito da leitura e da produção de textos nas línguas Kaingang e Portuguesa. A primeira por representar a identidade dos indígenas e a segunda por ser considerada a língua oficial do Brasil.

Uma das línguas que mais atuam aqui no Brasil é a língua portuguesa, mas a gente sabe que a nossa língua também é de grande importância. E a gente perdeu muitas

\footnotetext{
${ }^{5}$ Utilizamos para este trabalho a edição publicada em 2017.
} 


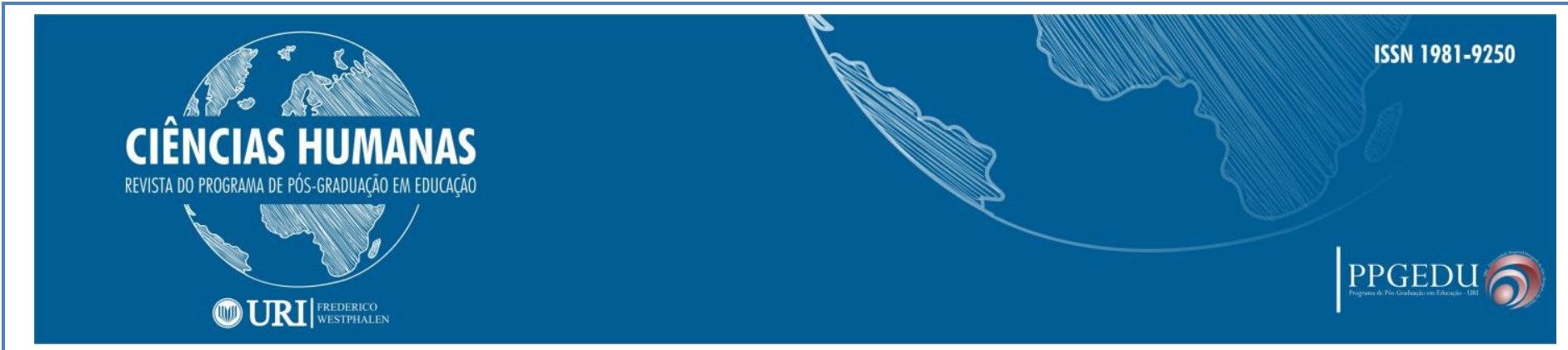

histórias, muitos casos passados que a gente agora podia ter e contar para os nossos filhos. Vamos supor, você sabe de uma história que é Yawaxikunawa. Antes de você morrer, se você não contar para o seu filho, o seu filho não vai saber nada dessa história. Então a gente quer registrar um pouquinho dos mitos. (MANÁ, apud RCNEI, 1998, p. 126).

Desse modo, a valorização da tradição oral também provoca o aluno a escrever, reescrever as histórias dos antepassados, além de ser importante prática para o desenvolvimento o aprimoramento da leitura. Foi extremamente importante reconhecer com os estudantes aspectos da tradição do povo kaingang que ainda se mantêm viva. Essa tradição pode ser compreendida ainda como um estado da arte não formal de educação e, desse modo, contribuir para a formação de uma política e de uma prática educacional adequadas, capazes de atender as necessidades da realidade atual das escolas indígenas. Nessa direção, é possível reiterar o que aponta D'Angelis,

Com certeza é mais fácil acomodar-se à situação em que os estados dominam as escolas nas áreas indígenas e impõe professores, currículo e material didático. Porém, acomodar-se a essa situação é submeter-se mais uma vez aos não-índios, contraditoriamente no momento em que, em nível nacional, existe apoio legal e institucional para os povos indígenas conquistarem seus currículos próprios: a Constituição Federal, as Diretrizes do Ministério da Educação e a existência de um Comitê de Educação Escolar Indígena no MEC. (D’ANGELIS, Vilmar, 2002, p. $125)$.

Por um lado as políticas inerentes à educação escolar indígena dependem do envolvimento da escola para se tornarem efetivas. Mas por outro, além do trabalho dos professores em sala de aula, é necessária a presença da comunidade indígena no cotidiano escolar e dos saberes que ela pode compartilhar e, neste caso, as lendas devem ser observadas como fontes do imaginário, da cultura, dos modos de percepção do mundo e devem estar presentes na formação intelectual e cultural dos jovens indígenas.

\section{FUNÇÕES DA LITERATURA DE TRADIÇÃO ORAL E SUAS IMPLICAÇÕES PARA A FORMAÇÃO LITERÁRIA}

A manifestação de qualquer expressão intelectual, por meio da palavra deve ser compreendida no âmbito da Literatura, a qual não se restringe apenas ao texto escrito, apesar dele ser a forma mais comum de reconhecê-la, tendo em vista a relação entre literatura e letras. No entanto, a palavra pronunciada, falada, é uma forma de expressão independente da escrita, designando o fenômeno literário, mais amplo e complexo anterior ao alfabeto. Se isso não fosse

\begin{tabular}{c|c|c|c}
\hline Rev. Ciências Humanas & Frederico Westphalen, RS & Pg. 05-18 & Maio/Agosto 2019 \\
\hline \multicolumn{2}{c|}{ Recebido em: 12/06/2019 } & Aceito em: 15/08/2019 \\
\hline
\end{tabular}




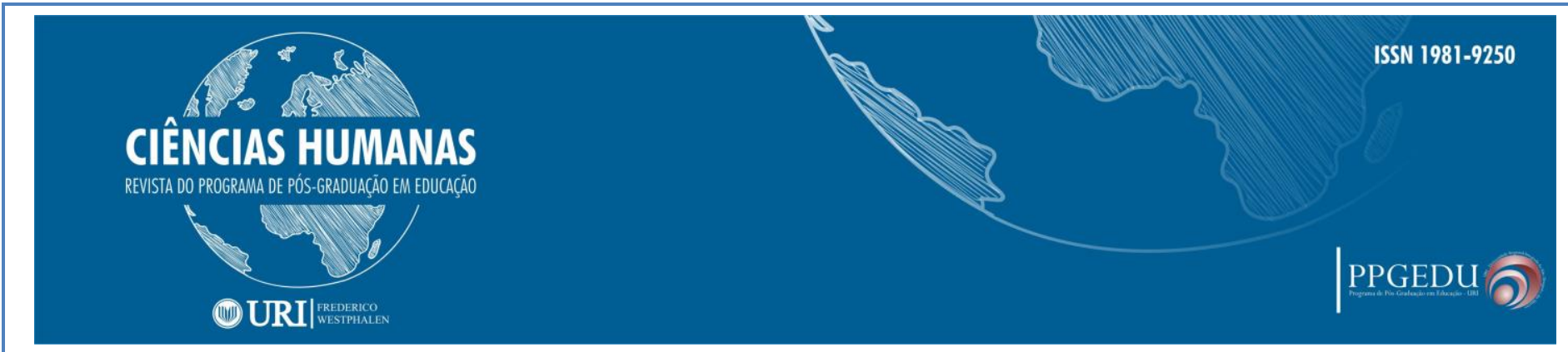

considerado estaríamos negando a Literatura dos iletrados, daqueles sem instruções literárias.

Essa característica da Literatura permitiu a aproximação da tradição oral kaingang e suas correlações com as conhecidas lendas da tradição universal.

Desse modo, caberia refletirmos sobre a existência de um determinado conceito de literatura? Podemos encontrar diferentes modos de pensar designações para o termo literatura, como arte da palavra, como fuga da realidade, transfiguração do real, como conhecimento de mundo e instrumento político, discussões que vêm desde a Poética de Aristóteles, mas ainda assim não teremos uma definição. Para Culler (1999) não devemos fazer a pergunta, o que é literatura? mas, o que nos faz tratar algo como literatura? O que a diferencia de textos comuns é o fato de ter passado pelo crivo institucional e de atribuição de valor. "E muitos dos traços da literatura advêm da disposição dos leitores de prestar atenção, de explorar incertezas e não perguntar de imediato 'o que você quer dizer com isso?'"(CULLER, 1999, p.33). Não nos interessa apenas dizer se uma obra é ou não literária, aprendemos com os estudiosos a observá-la enquanto categoria histórica e a refletir sobre as funções sociais, políticas que ocupa. Parece-nos que a incompreensão desses aspectos contribuem também para o desprestígio da literatura de tradição oral em sala de aula.

O próprio Culler (1999), importante referência nos estudos linguísticos e literários, retoma Kant para dizer que os objetos estéticos "'tem uma finalidade sem fim'" e são criados de tal maneira que faz suas partes operarem simultaneamente para certo fim. Vejamos:

\begin{abstract}
Mas o fim é a própria obra de arte, o prazer na obra ou o prazer ocasionado pela obra, não algum propósito externo. Em termos práticos, isso significa que considerar um texto como literatura é indagar sobre a contribuição de suas partes para o efeito do todo mas não considerar a obra como sendo principalmente destinada a atingir algum fim, tal como nos informar ou persuadir. Quando digo que as histórias são elocuções cuja relevância reside em sua 'narratividade', estou observando que há uma finalidade nas histórias (qualidades que podem torná-las boas histórias) mas que isso não pode ser facilmente vinculado a algum propósito externo e, dessa maneira, estou registrando a qualidade estética, afetiva das histórias, mesmo as não-literárias. Uma boa história é narrável, atinge os leitores ou ouvintes como algo que 'vale a pena'. Ela pode divertir ou instruir ou incitar, pode ter uma gama de efeitos, mas você não pode definir as boas histórias em geral como sendo aquelas que fazem qualquer uma dessas coisas. (CULLER, 1999, p.40)
\end{abstract}

Mesmo desconhecendo as disciplinas de ler e escrever, os povos primitivos, e alguns grupos de pessoas na atualidade, produziram cânticos, lendas, mitos, histórias; demonstraram e demonstram suas experiências e regras de conduta com provérbios, adivinhações,

\begin{tabular}{l|c|c|c}
\hline Rev. Ciências Humanas & Frederico Westphalen, RS & Pg. 05-18 & Maio/Agosto 2019 \\
\hline
\end{tabular}

\begin{tabular}{l|l} 
Recebido em: 12/06/2019 & Aceito em: 15/08/2019
\end{tabular}




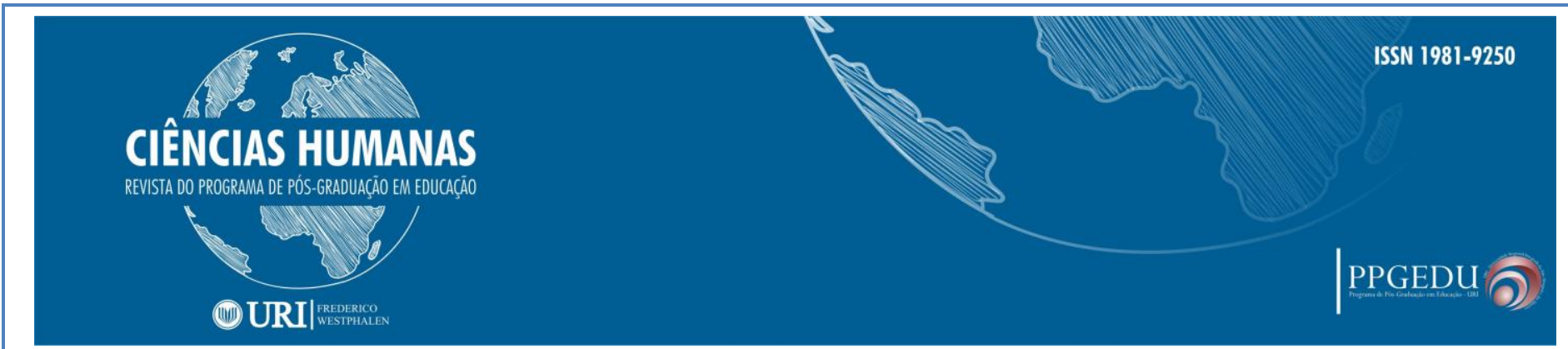

dramatizações, o que nos faz reconhecer a existência de um patrimônio que, desde a antiguidade, vem se difundindo de memória em memória e sobrevivendo por meio da literatura de tradição oral. Esses foram elementos importantes para considerarmos o saber indígena kaingang na aulas de língua portuguesa e literatura.

Histórias que conhecemos na atualidade, reconhecidas como os clássicos da Literatura Infanto-Juvenil, percorreram um longo caminho desde a Antiguidade. Com algumas transformações ou adaptações foram classificadas pelos pesquisadores folcloristas e reconhecidas pelos intelectuais literários. Podemos mencionar alguns dos contos que fizeram esse percurso: Chapeuzinho Vermelho, João e Maria, A Bela Adormecida, Rapunzel dentre outros foram recolhidos da cultura popular europeia, ainda do século XIX, pelos alemães Jacob e Wilhelm Grimm. Mas com certeza essas histórias já existiam bem antes de serem coletadas. (DARNTON, 1986, p. 31). Como notamos, essas colocações corroboram as anteriormente destacadas por D'Angelis e Romero.

Luís da Câmara Cascudo, um dos mais respeitáveis pesquisadores do folclore e da etnografia do nosso país, em depoimento concedido à TV cultura, em 1978, afirma:

[...] eu gostaria de saber qual o traço mais marcante da cultura popular brasileira. Gostaria de saber, pelo seguinte, porque uma cultura popular é milenária e contemporânea. É de todas as épocas e do momento. A nossa vem das fontes mais antigas e variadas. Das indígenas, de onde vieram os nossos indígenas, quais as fontes étnicas culturais deles; quantas raças a África exportou nos navios negreiros para o Brasil. Cada grupo étnico era uma cultura, uma memória, uma projeção na nascente cultura brasileira, que era a miscigenação. Portugal é um tabuleiro de raças. Ali estavam todos os romanos, os celtas, os árabes e tudo isso veio para o Brasil, e naturalmente, logicamente, desse atrito a forma foi a mais inesperada, e a força de concentração mantém os elementos perenes, mas o tempo vai diferenciando, aculturando todas essas coisas.

De acordo com Cascudo a literatura oral é um mundo atraente de caráter realista que dá testemunho de uma fonte arqueológica. (CASCUDO, 2002, p. 690). Antes de serem reconhecidos como literários os contos eram fundamentalmente da tradição oral dos povos. Atravessaram gerações, memórias e sobreviveram na Antiguidade, na Idade Média, na Renascença até os séculos XVIII, XIX e XX. Às vezes mudavam as temáticas, criavam novos focos narrativos, mas durante o passar dos anos mantiveram as características centrais como os desentendimentos familiares, amores proibidos, a miséria, entre outros temas. Camponeses e amas de casa davam vida à literatura de tradição oral. De modo geral o povo buscava nas histórias

\begin{tabular}{l|l} 
Recebido em: 12/06/2019 & Aceito em: 15/08/2019
\end{tabular}




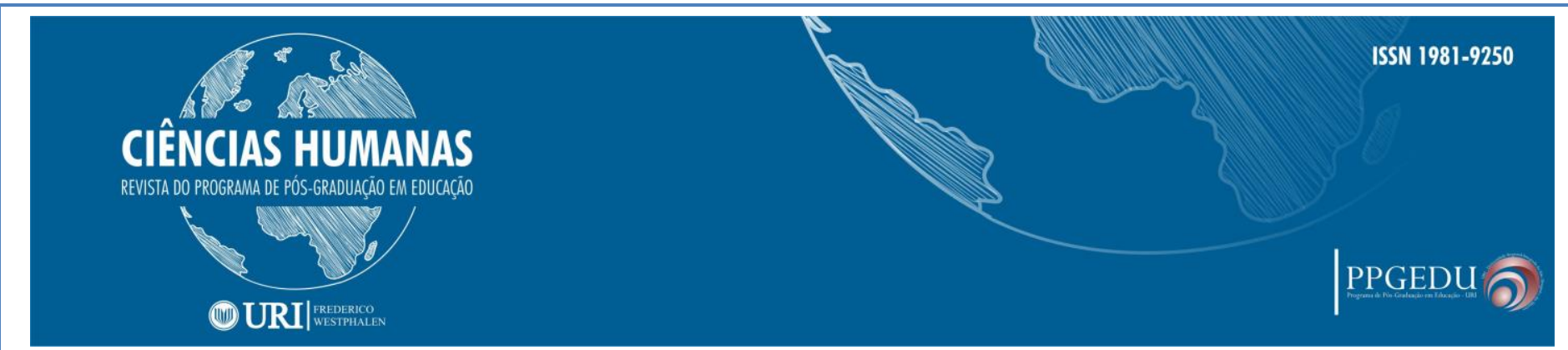

a explicação para fenômenos inexplicáveis e também as utilizavam na educação dos filhos. Os causos assustadores eram contados para amedrontar as crianças e evitar que elas infringissem as regras.

Como destacamos a literatura precede a escrita, por meio da oralidade diferentes povos compuseram seus cânticos, suas histórias, suas lendas, perpetuando seus conhecimentos através dos tempos, utilizando a própria palavra como instrumento mágico. Reconhecidamente, os registros das tradições orais são considerados as primeiras manifestações do que foi compreendido como literatura infantil, podendo ser uma escrita direta, sem acréscimos, reduções ou ornamentos, como ocorre na coleção de contos dos Irmãos Grimm, ou, podem sofrer influências estilísticas do autor, como nos casos dos contos e fábulas dos escritores franceses Charles Perrault, Madame d'Aulnoy e de Jean de La Fontaine. Os contos recolhidos por esses pesquisadores folcloristas sofreram inúmeras adaptações, foram reescritos e modificados, segundo o espírito do autor em cada época e as diferentes adaptações consideravam como pano de fundo os contextos socioculturais e históricos.

Charles Perrault, Madame d'Aulnoy e os Irmãos Grimm destacam-se como grandes escritores por coletarem narrativas que se encontravam ainda sob forma oral entre a gente do povo. Os textos eram retirados da literatura popular e escritos para que perdurassem. A obra Contos de fadas para crianças e adultos, dos Irmãos Grimm, material folclórico recolhido e publicado entre os anos 1812 e 1822, trazia narrativas que misturam o humanismo com o sentido maravilhoso da vida, predominando a esperança e a confiança na vida das pessoas. Não fosse o trabalho desses folcloristas em fazer os registros, essa tradição não teria chegado até nós.

Os Irmãos Grimm foram pesquisadores preocupados em pesquisar, ouvir, contar e registrar os contos. Uma de suas pesquisas tinha como objetivo o "[...] levantamento dos elementos linguísticos para fundamentação do estudo da língua alemã do ponto de vista filológico e a fixação dos textos do folclore literário germânico como expressão cultural do povo.” (GRIMM, 1981, p.29). Assim percorreram regiões, registrando as narrativas orais que eram contadas pela população. Os Irmãos Grimm reuniam-se com seus companheiros para analisar e organizar as histórias. Os contos ouvidos na infância eram reelaborados pela memória. Assim, eles “[...] transmitiam aos ouvintes sua bagagem de conhecimento do acervo folclórico.” (GRIMM, 1981, p.29).

Charles Perrault, erudito acadêmico francês, advogado, poeta, prosador, contador de histórias, conhecedor da literatura e das artes, destacou-se e foi consagrado mundialmente com a 


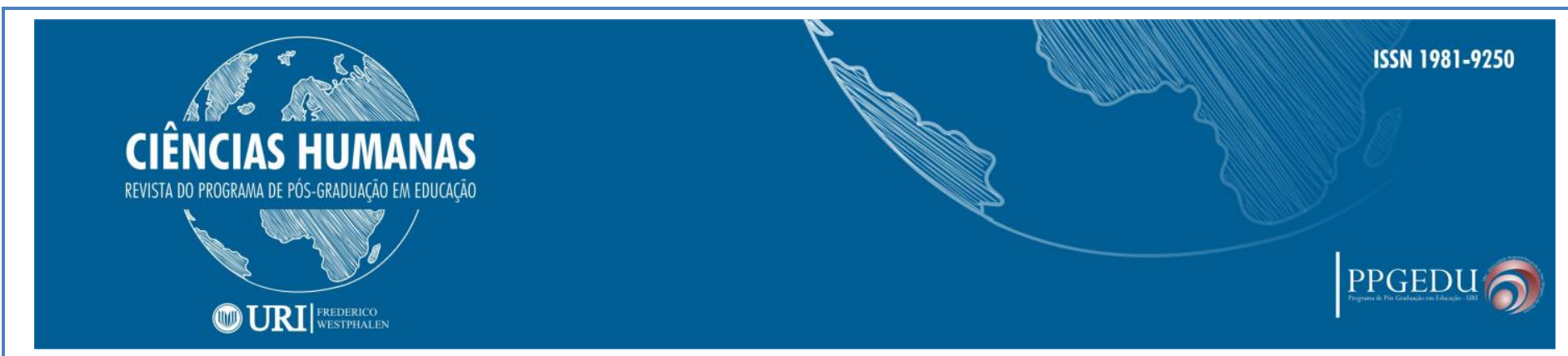

publicação da obra Contos da Mamãe Gansa, em 1697. Pelas características estilísticas esta obra é considerada um marco para os contos de fadas enquanto gênero literário. Para o autor a literatura era resultado da valorização da fantasia e da imaginação e os contos deveriam ser uma espécie de cartilha da boa educação.

Outro destaque no panorama da história da Literatura foi o dinamarquês Hans Christian Andersen, o qual teve 168 contos publicados entre 1835 e 1872. É considerado mestre da arte do conto de fadas, e suas obras têm popularidade universal. Ainda que a literatura do autor apresente raízes na lenda popular, elas são de estilo pessoal com elementos autobiográficos e sátira social contemporânea. Andersen parte de suas próprias vivências para inspirar suas histórias, dando ênfase ao cotidiano e a realidade concreta, utilizando-se do fantástico e do maravilhoso para amenizar as dificuldades da vida. Apesar dele também ter escrito para adultos, foram os seus contos de fadas que o tornaram famoso. Como reconhecimento a sua contribuição literária no dia 2 de abril, data de seu nascimento, é comemorado o Dia Internacional do livro Infanto-Juvenil.

Os autores mencionados são o berço da organização da literatura infanto-juvenil. Foram e ainda são inspiração para que surjam os contemporâneos e também para que a literatura se fortaleça e continue mobilizando novos públicos leitores. Desse modo, é complexo distinguir entre histórias de origem literária e oral, porque os contos folclóricos receberam tratamento literário desde os primeiros tempos e, inversamente, os contos literários encontraram seu caminho de volta à tradição oral. Ao que nos faz reiterar a importância do trabalho com a tradição oral indígena na sala de aula, a valorização da memória dos mais velhos é um meio de instigar os jovens a conhecerem a história dos antepassados.

\section{CONSIDERAÇÕES}

Buscamos demonstrar neste texto o modo como algumas atividades desenvolvidas por professores e acadêmicos da Licenciatura Intercultural Indígena em Línguas, Artes e Literaturas puderam justapor conteúdos do currículo desse curso com o cotidiano da comunidade indígena. Uma forma de mobilizar o presente, reconhecer o passado e propor outras perspectivas para o futuro, tendo como foco propositivo o trabalho em sala de aula.

Apresentamos alguns aspectos que sintetizaram a importância da cultura popular e do trabalho desenvolvido por folcloristas para a formação da literatura universal. Registros históricos

\begin{tabular}{l|c|c|c}
\hline Rev. Ciências Humanas & Frederico Westphalen, RS & Pg. 05-18 & Maio/Agosto 2019 \\
\hline
\end{tabular}

\begin{tabular}{l|l} 
Recebido em: 12/06/2019 & Aceito em: 15/08/2019
\end{tabular}


da cultura francesa do século XVII assinalam aspectos da natureza, função e origens da literatura infanto-juvenil, categorias que auxiliam na elaboração de conceitos desse gênero, formulados por diferentes autores. O conhecimento do trabalho de folcloristas europeus e brasileiros trouxe subsídios para articular a literatura do reconhecido cânone com a tradição oral kaingang.

$\mathrm{O}$ amadurecimento desse olhar sobre a cultura indígena a qual se perpetua nas narrativas contadas pelos mais velhos aos mais jovens, poderá ser responsável pelo reconhecimento e revitalização dessa tradição na comunidade, mas dependerá de intenso trabalho nas escolas, de modo interdisciplinar. A literatura pode ser a força para alavancar atitudes de protagonismo dos professores e alunos em direção a novos modos de ler e compreender a tradição oral no contexto indígena.

\section{REFERÊNCIAS}

CASCUDO, Luiz da Câmara. Contos tradicionais do Brasil. 18.ed. RJ: Ediouro, 2002.

Depoimento concedido para a TV Cultura da Secretaria de Cultura, Ciência e Tecnologia do Governo do Estado de São Paulo. São Paulo, 1978. Disponível em: <http://www.memoriaviva.com.br/cascudo/index2.htm>. 30 jul. 2015.

CULLER, Jonathan. Teoria literária: uma introdução, São Paulo: Beca Produções Culturais Ltda, 1999.

DARNTON, Robert. O grande massacre dos gatos: e outros episódios da história cultural francesa. 2. ed. RJ: Graal, 1986, Trad. Sonia Coutinho.

D’ANGELIS, Wilmar da Rocha. Kaingáng: Questões de Língua e Identidade. LIAMES n. 2. Campinas: Editora da Unicamp, p. 105-128, 2002. Disponível em:

$<$ https://periodicos.sbu.unicamp.br/ojs/index.php/liames/issue/archive >. Acesso em: 04 jan. 2019.

GRIMM, Jacob, Wilhelm. Joãozinho e Mariazinha. Porto Alegre-Krarup. $7^{\text {a }}$ ed. 1981.

BRASIL, Ministério da Educação e do Desporto. Lei de diretrizes e bases. Brasília: Congresso Nacional, dezembro, 1996.

Ministério da Educação e do Desporto, Secretaria de Educação Fundamental.

Referencial curricular nacional para as escolas indígenas. Brasília: MEC/SEF, 1998.

, Ministério da Educação, Secretaria de Educação Fundamental. Departamento de Política da Educação Fundamental, Coordenação-geral de Apoio às Escolas Indígenas. Referenciais para a formação de professores indígenas. Brasília: MEC/SEF, 2002.

ROMERO, Sílvio. Contos populares do Brasil. v. 3. Jundiaí: Cadernos do Mundo Inteiro, 2017. 